\title{
Treatment Options for the Atrophic Posterior Maxilla
}

\author{
Ismael Khouly, DDS, MS, PhD; ${ }^{1}$, Diego Gallego Rivero, DDS ${ }^{2}$;, Alejandro Perez, $\mathrm{DDS}^{2}$; Said \\ Khouly, DDS, MS ${ }^{3}$; Sang-Choon Cho, DDS ${ }^{2}$; Stuart J. Froum, DDS ${ }^{2}$ \\ ${ }^{1}$ Department of Oral \& Maxillofacial Surgery, New York University College of Dentistry, New York, USA; Bluestone \\ Center for Clinical Research, New York University College of Dentistry, New York, USA \\ ${ }^{2}$ Department of Periodontology and Implant Dentistry, New York University College of Dentistry, New York, USA \\ ${ }^{3}$ Private Practice, San Sebastian, Spain
}

\begin{abstract}
Maxillary sinus augmentation has been shown to be a predictable surgical procedure used to enhance bone volume for the placement of dental implants in the atrophic posterior maxilla. Therefore, various techniques have been proposed in order to achieve the necessary bone dimension for the insertion of implants in previously compromised sites. Careful case and material selection corresponding to different indications can be beneficial to achieving predictable and consistent treatment outcomes in the posterior atrophic maxilla.

The purpose of this review was to discuss the indications, contraindications, limitations, and case selection criteria used to determine treatment options for the different techniques. It is necessary to define case selection criteria according to the remaining crestal bone and the anatomy of the sinus cavity.
\end{abstract}

Keywords: Maxillary sinus augmentation; dental implant; osteotome; lateral wall; bone graft

\section{INTRODUCTION}

Implant therapy for rehabilitation of edentulous posterior maxillary regions often presents a challenge due to inadequate alveolar ridge and poor quality of bone. Resorbed alveolar processes result from a combination of pneumatization of the maxillary sinus, the effects of periodontal disease, and physiological bone resorption. Therefore, various techniques have been proposed in order to achieve the necessary bone volume for the insertion of implants in the atrophic posterior maxillar. (1-4) During the past few decades, maxillary sinus augmentation has been shown to be the most predictable of the preprosthetic surgical techniques used to enhance bone volume for the placement of dental implants in previously compromised sites.5-8

Although there have been some modifications, the most common approach is the Lateral Wall Sinus Floor Elevation (LWSFE), whereby an osteotomy "window" in the lateral wall of the sinus is made for access, sinus membrane elevation and packing the floor of the sinus with a graft material.1-5 Implants can be placed simultaneously with the grafting procedure or after a healing and graft consolidation period of 4 to 9 months. Elevation of the sinus membrane can also be accomplished with the transcrestal approach to the maxillary sinus, known as the Bone Added Osteotome Sinus Floor elevation (BAOSFE) that has been advocated as "minimally invasive". $(3,4,9)$ However, some limitations related to these techniques have been reported. $(7,10,11)$ In order to reduce these complications, other approaches have been proposed, including, but not limited to, the use of short implants and Osteotome-Assited Sinus Augmentation (OASA) technique. (12-20)

It is necessary to define case selection criteria according to the remaining crestal bone and the anatomy of the sinus cavity. The purpose of this review was to discuss the indications, contraindications, limitations, and case selection criteria used to determinethe most predictable treatment options of the different techniques.

\section{MATERIALS AND METHODS}

A search of the literature was performed focusing on techniques related to the sinus augmentation procedure. Clinical data in this study was obtained from the anonymous Implant Database (ID) at the Ashman Department of Periodontology and Implant Dentistry at the New York University College of Dentistry (NYUCD) Kriser Dental Center. This Data was extracted as deidentified information from the routine treatment of patients. The ID was certified by the Health Insurance Portability and Accountability act (HIPAA) and approved by the University Committee on the Activities involving Human Subjects (UCASHS). A computer search of electronic databases from MEDLINE and PUBMED at the Waldman Library at the NYUCD Kriser Dental Center was performed. Keywords such as "maxillary sinus," "sinus lift," "sinus augmentation," "sinus elevation," "sinus graft," "bone grafting," "dental implants," and "endosseous implants" were used, alone and in combination, to search the databases. Non-

\section{ACTUALIDAD M É D I C A www.actualidadmedica.es} (c)2014.Actual.Med. Todoslos derechosreservados
Ismael Khouly, DDS, MS, PhD

Phone: 212-998-9453 - Fax: 212-995-4843

Email: dr.ismaelkhouly@gmail.com

421 First Avenue - BCCR 2W

New York, NY 10010 
English language publications were excluded. The search was limited to studies involving human subjects. Restrictions were not placed regarding the type of study design.

\section{RESULTS}

A total of 15 articles from reviewed journal published in English were collected from a search performed using Medline and Pubmed at the Waldman Library at the NYUCD Kriser Dental Center. The following guideline tables are the result of this literature review (TABLES 1, 2).

\begin{tabular}{|l|l|}
\hline $\begin{array}{c}\text { Residual Bone } \\
\text { Height (mm) }\end{array}$ & \multicolumn{1}{|c|}{ Procedure } \\
\hline$<4$ & $\begin{array}{l}\text { Lateral wall, staged approach (delayed } \\
\text { placement)* }\end{array}$ \\
\hline $4-7$ & OASA Technique \\
\hline $8-10$ & Osteotome Technique \\
\hline
\end{tabular}

Table 1. Treatment options for atrophic posterior maxilla for single implant. *Simultaneous implant placement if primary stability is achieved (V-Shape sinus).

\begin{tabular}{|l|l|}
\hline $\begin{array}{c}\text { Residual Bone } \\
\text { Height (mm) }\end{array}$ & \multicolumn{1}{|c|}{ Procedure } \\
\hline$<4$ & $\begin{array}{l}\text { Lateral wall, staged approach (delayed } \\
\text { placement)* }\end{array}$ \\
\hline $4-7$ & Lateral wall, simultaneous placement \\
\hline $8-10$ & Osteotome Technique \\
\hline
\end{tabular}

Table 2. Treatment options for atrophic posterior maxilla for multiple implants. *Simultaneous implant placement if primary stability is achieved (V-Shape sinus).

\section{DISCUSSION}

Due to the improvement of surgical techniques and the progress of research in the field of biomaterials, excellent outcomes have been reported for implant-supported rehabilitations in the atrophic posterior maxilla in the past years. $(21,22)$ The most commonly utilized augmentation method for maxillary sinus reconstruction was first presented by Tatum 19772, and published by Boyne and James in 19801, using a window through the lateral wall of the alveolus for sinus access. The LWSFE technique has been widely described in the literature and is recommended with a residual bone height less than 4 to $5 \mathrm{~mm}$. This procedure has been shown to be highly predictable for implant therapy with an overall implant survival rate well beyond 90\%. 5,6,7,23 Advantages of the lateral window (LWSFE) approach to the sinus include direct view of the sinus cavity, access to the Schneiderian membrane, and an appropriate graft material placement15 (Fig.1, 2). However, this procedure presents the disadvantages of prolonged time, cost, and morbidity for the patient. $(24,25)$

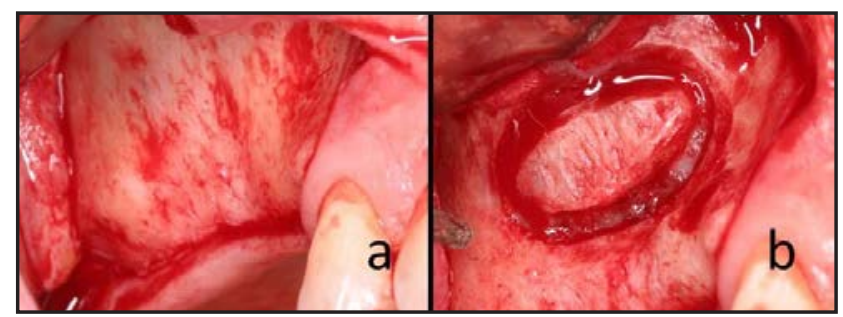

Fig. 1a. Intraoperative view of lateral wall of the maxillary sinus with Full thickness flap; Fig. 1b: Osteotomy of lateral wall window.

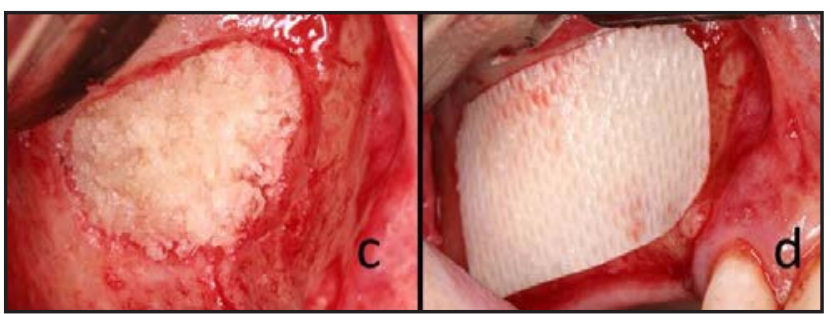

Fig. 1c: Placement of bone graft material in the sinus cavity; Fig. 1d: Resorbable membrane secured over the lateral window.

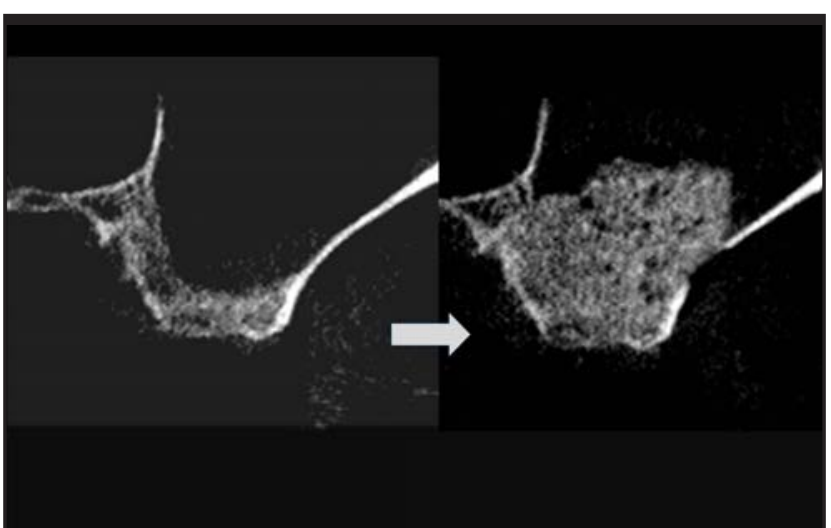

Fig. 2. Paraxial CT scans of sinus taken pre and post surgery.

To reduce complications and trauma that may occur using the lateral wall approach, different techniques have been proposed. The transcrestal approach to the maxillary sinus (BAOSFE) has been advocated as 'minimally invasive' because of the undisturbed vascularization of the graft and less postoperative morbidity.4,9 According to standard protocol, the osteotome technique should be used when the ridge height is greater than 4 to $5 \mathrm{~mm}$ where implants are placed simultaneously with the elevation of the sinus floor (Fig.3). $(3,4)$ Recently, a systematic review of the literature showed that crestal sinus lift can be an effective treatment option, reporting a mean weighted survival rate of $95 \%$ after 5 years of function. 26 The same review also showed that the majority of failures occurred during the first year after treatment. However, limitations of this procedure include: limited accessibility and visibility for elevation of the sinus membrane and inability to diagnose and treat membrane perforations. $(27,28,10)$ When the membrane is lifted more than $3 \mathrm{~mm}$, the risk of membrane perforation increases significantly. $(29,30)$ The use of an endoscope has been proposed to diagnose the membrane perforation during BAOSFE, increasing the cost and time of the procedure. $(29,30)$ Thus, in cases where crestal height is 4-7 mm and an implant length of $10-13 \mathrm{~mm}$ is desired, the sinus membrane will be lifted greater than $3 \mathrm{~mm}$, increasing the risk of membrane perforation. An additional complication reported following the use of osteotomes is paroxysmal positional vertigo. (9) 


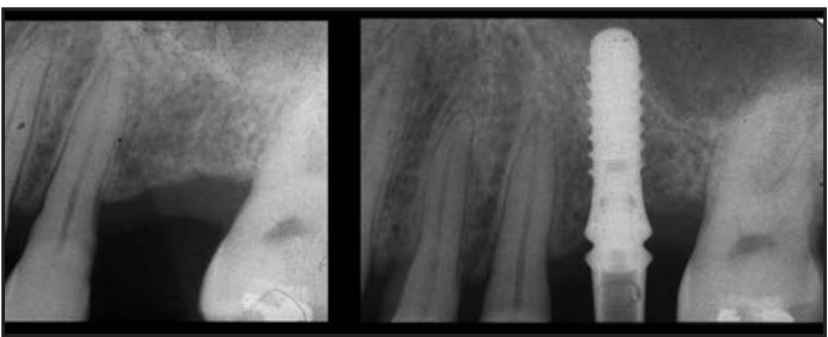

Figure 3. Periapical X-Rays of implant placed using BAOSFE technique, prior to surgery and 6 months post-surgery.

A modified transcrestal approach with a vertical slot osteotomy (OASA technique) was proposed to provide good visual access in order to reflect the Schneiderian membrane at the inferior border of the sinus floor, avoid perforation of membrane, obtain access to repair membrane perforation, and have control of bone graft placement.(15) Drilling with direct vision and protection of the membrane avoided the trauma of the osteotome touching the membrane, which also decreased the chances of perforation related to the tapping sequence. $(31,32)$ However, this procedure may increase time and morbidity to the patient. (15)

Currently, which bone graft material is most effective for these techniques is unknown. A number of clinical studies using a variety of autogenous bone grafts, allografts, xenografts, and alloplast in the posterior maxilla have been conducted and were discussed in a number of systematic reviews. (5-8,3337) As described in the literature, such heterogeneity had no relevant effect on the clinical outcomes. $(38,39)$ Although, sinus augmentation without graft have been reported successfully using lateral wall or osteotome procedures. $(40,41)$ Moreover, no significant difference in outcomes were reported between studies using bone graft materials during sinus augmentation versus no graft material. (26) The surgical concern is how to achieve better blood supply and better stability for placed implants, while avoiding trauma.

Recently, short implants (less than $10 \mathrm{~mm}$ long) have been proposed as an alternative to sinus augmentation in order to rehabilitate posterior maxilla. $(13,14)$ The use of short implants may reduce the occurrence of surgical complications and avoid augmentation procedures reducing patient's discomfort. $(13,14,42)$ Prior to placement of short implants the residual bone height and width must be evaluated carefully. There must be sufficient residual volume to accommodate the implants ensuring primary stability. The use of short implants is promising but needs further investigation to be considered as effective as the other techniques in the long term. (43)

A careful evaluation of the sinus anatomy is mandatory prior to any surgical procedure involving the sinus. Studies by Avila et al (44) and Soardi et al (45) reported that a direct relation exists between sinus morphology and vital bone formation. The results of these studies demonstrated that sinuses with a narrow horizontal width and greater exposure of the medial and lateral walls showed a greater percentage of vital bone than sinuses with a wider width and less surrounding bone exposure. They showed that significant time is necessary for graft maturation, especially in wide sinuses. Since the blood supply to the sinus is critical for healing and bone formation any factor that brings this supply closer to the graft material would be expected to improve healing. For example, a sinus with a narrow horizontal width, closer proximity of surrounding walls, and V-shaped allows better blood supply and better stability when implants are placed simultaneously. (Fig. 4, 5) The implants will support the Schneiderian membrane and the site can heal even without adding bone grafting. In narrow maxillary sinuses, the higher amount of remaining residual crestal bone and presence of slope, the osteotome procedures may be recommended. A smaller width and height would allow cells and healing proteins less distance to migrate. However, wide, U-shaped sinuses may provide less chances of blood supply. For cases with less of crestal bone and a flatter sinus floor in wide sinus, a conventional sinus augmentation with lateral wall procedure may provide more predictable outcomes.

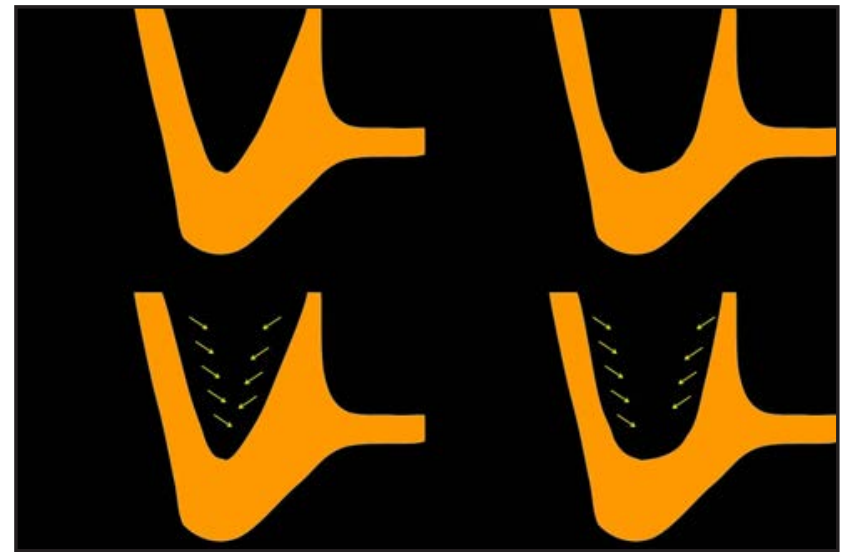

Figure 4. Relation between sinus morphology and vital bone formation.

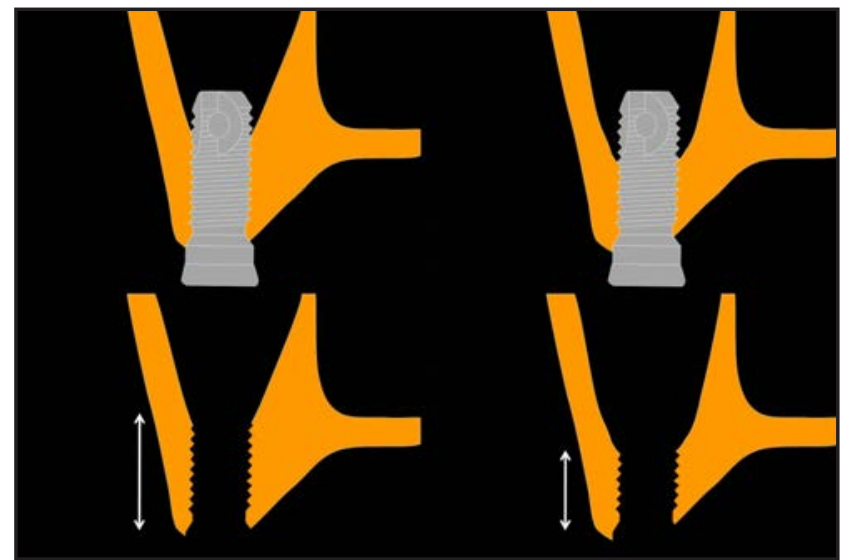

Figure 5. Implant stabilization regarding the sinus shape ( $V$-shaped vs U-shaped)

\section{CONCLUSIONS}

The primary purpose of sinus lift procedure is to create sufficient bone structure to allow implant placement and its posterior prostheses in a predictable way. Which technique to use depends on the ability and experience of the operator and the anatomical characteristics of the remaining bone. Based on the remaining bone, the following guidelines are suggested: with a residual bone height (RBH) of $4 \mathrm{~mm}$ or less, a LWSFE procedure is recommended for single or multiple implant placement; with $4-7 \mathrm{~mm}$ of RBH, a OASA technique is recommended for single implants and a LWSFE for multiple implant placement; with more than $7 \mathrm{~mm}$ of RBH, BAOSFE can be used. Simultaneous implant placement is recommended whenever primary stability can be obtained, this occurs more often in V-shaped sinuses.

Using the proposed guidelines, careful case and material selection corresponding to different indications can be beneficial to achieve predictable treatment outcomes in the posterior atrophic maxilla. Even though sinus lift procedures have been thoroughly studied for several years, further studies including sinus anatomy should assess improvements in this field. 


\section{REFERENCES}

1. Boyne PJ, James RA. Grafting of the maxillary sinus floor with autogenous marrow and bone. J Oral Surg 1980; 38: 613-616.

2. Tatum H Jr. Maxillary and sinus implant reconstructions. Dent Clin North Am 1986; 30: 207-229.

3. Summers, R.B. A new concept in maxillary implant surgery: the osteotome technique. Compendium 1994; 15: 152-158.

4. Summers, R.B. The osteotome technique: part 3-less invasive methods of elevating the sinus floor. Compendium 1994; 15 : 698-702

5. Aghaloo T, Moy PK. Which hard tissue augmentation techniques are the most successful in furnishing bony support for implant placement? Int J Oral Maxillofac Implants 2007; 22(supp): 49-70.

6. Wallace SS, Froum SJ. Effects of maxillary sinus augmentation on the survival of endosseous dental implants. A systemic review. Ann Periodontol 2003; 8: 328-343.

7. Del Fabbro M, Testori T, Franceitti L, Weinstein R. Systemic review of survival rates for implants placed in the grafted maxillary sinus. In J Periodontics Restorative Dent 2004: 24: 565-578.

8. Van Den Bergh JP, ten Bruggenkate CM, Krekeler G, Tuinzing DB Maxillary sinus floor elevation and grafting with human demineralized freeze dried bone. Clin Oral Implants Res 2000; 11: 487-493.

9. Engelke W, Schwarzwaller W, Behnsen A, Jacobs HG. Subantroscopic laterobasal sinus floor augmentation (SALSA): an up-to-5-year clinical study. Int J Oral Maxillofac Implants. 2003; 18(1): 135-143.

10. Di Girolamo M, Napolitano B, Arullani CA, Bruno E, Di Girolamo S. Paroxymal positional vertigo as a complication of osteotomesinus floor elevation. Eur Arch Otorhinolaryngol 2005; 262: 631-633.

11. Penarrocha-Diago M, Rambla Ferrer J, Perez V, Perez-Garrigues $\mathrm{H}$. Benign paroxysmal vertigo secondary to placement of Maxillary implants using the alveolar expansion technique with osteotome: a study of 4 cases. Int J Oral Maxillofac Implants. 2008; 23: 129-132.

12. Stelzle F, Benner KU. Evaluation of different methods of indirect sinus floor elevation for elevation heights of $10 \mathrm{~mm}$ : an experimental ex vivo study. Clin Implant Dent Res. 2011 Jun; 13(2): 124-133.

13. Annibali S, Cristalli MP, Dell'Aquila D, Bignozzi I, LaMonaca G, Pilloni A. Short dental implants: a systematic review. J Dent Res 2012; 91: 25-32.

14. Esposito M, Cannizzaro G, Soardi E, et al. Posterior atrophic jaws rehabilitated with prostheses supported by $6 \mathrm{~mm}$-long, 4 $\mathrm{mm}$-wide implants or by longer implants in augmented bone. Preliminary results from a pilot randomised controlled trial. Eur J Oral Implantol 2012; 5: 19-33.

15. Froum S, Cho SC, Cayarga R, Khouly I. Osteotome-Assited Sinus Augmentation Procedure for Single Implant Palcement in the Atrophic Posterior Maxilla. Dental Learning. 2012 (4); Sept:1-16.

16. Jung UW, Hong JY, Lee JS, Kim CS, Cho KS, Choi SH. A hybrid technique for sinus floor elevation in the severely resorbed posterior maxilla. J Periodontal Implant Sci 2010; 40(2): 76-85.

17. Bidra AS, Hyunh-Ba G. Implants in the pterygoid region: a systematic review of the literature. Int J Oral Maxillofac Surg 2011; 40(8): 773-781.

18. Candel E, Peñarrocha D, Peñarrocha M. Rehabilitation of the atrophic posterior maxilla with pterygoid implants: a review. J Oral Implantol 2012; 38: 461-466.

19. Chrcanovic BR, Abreu MH. Survival and complications of zygomatic implants: a systematic review. Oral Maxillofac Surg 2013; 17(2): 81-93.

20. Sharma A, Rahul GR. Zygomatic implants/fixture: a systematic review. J Oral Implantol. 2013; 39(2): 215-224.

21. Tonetti MS, Hammerle $\mathrm{CH}$. Advances in bone augmentation to enable dental implant placement: consensus report of the Sixth EuropeanWorkshop on Periodontology. J Clin Periodontol 2008; 35: 168-172.

22. Rickert D, Vissink A, Slater JJ, Meijer HJ, Raghoebar GM Comparison between conventional and piezoelectric surgical tools for maxillary sinus floor elevation. A randomized controlled clinical trial. Clin Implant Dent Relat Res 2013; 15 : 297-302.

23. Pjetursson BE, Tan WC, Zwahlen M, Lang NP. A systematic review of the success of sinus floor elevation and survival of implants inserted in combination with sinus floor elevation. $J$ Clin Periodontol 2008; 35(suppl): 216-224.

24. Nkenke E, Stelzle F. Clinical outcomes of sinus floor augmentation for implant placement using autogenous bone or bone substitutes: a systematic review. Clin Oral Implants Res 2009; 20 (Suppl 4): 124-133.

25. Chiapasco $\mathrm{M}$, Casentini $\mathrm{P}$, Zaniboni $\mathrm{M}$. Bone augmentation procedures in implant dentistry. Int J Oral Maxillofac Implants 2009; 24 (Suppl): 237-259.

26. Del Fabbro $M$, Corbella $\mathrm{S}$, Weinstein $\mathrm{T}$, Ceresoli $\mathrm{V}$, Taschieri S. Implant survival rates after osteotome mediated maxillary sinus augmentation: a systematic review. Clin Implant Dent Relat Res 2012; 14 (Suppl 1): e159-e168.

27. Aimetti M, Romagnoli R, Ricci G, Massei G. Maxillary sinus elevation: the effect of macrolacerations and microlacerations of the sinus membrane as determined by endoscopy. Int J Periodontics Restorative Dent 2001; 21: 581-589.

28. Berengo M, Sivolella S, Majzoub Z, Cordioli G. Endoscopic evaluation of the bone-added osteotome sinus floor elevation procedure. Int J Oral Maxillofac Surg 2004; 33: 189-194.

29. Nkenke E, Schlegel A, Schultze-Mosgau S, Neukam FW, Wiltfang J. The endoscopically controlled osteotome sinus floor elevation: a preliminary prospective study. Int J Oral Maxillofac Implants. 2002; 17: 557-566.

30. Ardekian L, Oved-Peleg E, Mactei EE, Peled M. The clinical significance of sinus membrane perforation during augmentation of the maxillary sinus. J Oral Maxillofac Surg. 2006; 64(2): 277-282.

31. Emmerich D, Att W, Stappert C. Sinus floor elevation using osteotomes: a systematic review and meta-analysis. J Periodontol. 2005; 76(8): 1237-1251.

32. Chiapasco M, Ronchi P. Sinus lift and endosseous implants-preliminary surgical and prosthetic results. Eur J Prosthodont Restor Dent. 1994 Sep; 3(1): 15-21.

33. Froum SJ, Wallace SS, Elian N, Cho SC, Tarnow DP. Comparison of mineralized cancellous bone allograft (Puros) and anorganic bovine bone matrix (Bio-Oss for sinus augmentation: Histomorphometry at 26 to 32 weeks after grafting. Int J 
Periodontics Restorative Dent 2006; 26: 543-551.

34. Froum SJ, Tarnow DP, Wallace SS, Rohrer MD, Cho SC Sinus floor elevation using anorganic bovine bone matrix (OsteoGraf/N) with and without autogenous bone: a clinical, histologic, radiographic, and histomorphometric analysis-Part 2 of an ongoing prospective study. Int J Peri Resto Dent 1998; 18: 528-543.

35. Froum SJ, Wallace S, Cho SC, Khouly I, Rosenberg E, Corby P, Froum S, Bromage T, Schoor R, Norman R, Tarnow DP. Histomorphometric comparison of different concentrations of recombinant human bone morphogenetic protein with allogeneic bone compared to the use of $100 \%$ mineralized cancellous bone allograft in maxillary sinus grafting. Int J Periodontics Restorative Dent. 2013 Nov-Dec;33(6):721-30.

36. Froum SJ, Wallace $S$, Cho SC, Rosenburg E, Froum S, Schoor R, Mascarenhas P, Tarnow DP, Corby P, Elian N, Fickl S, Ricci J, $\mathrm{Hu}$ B, Bromage T, Khouly I. A histomorphometric comparison of Bio-Oss alone versus Bio-Oss and platelet-derived growth factor for sinus augmentation: a postsurgical assessment. Int J Periodontics Restorative Dent. 2013; 33(3): 269-79.

37. Wheeler SL. Sinus augmentation for dental implants: the use of alloplastic materials. J Oral MaxSurg 1997; 55: 1287-1293.

38. Del Fabbro M, Wallace SS, Testori T. Long-term implant survival in the grafted maxillary sinus: a systematic review. Int J Periodontics Restorative Dent. 2013 Nov-Dec; 33(6): 773-83.

39. Chiapasco M, Casentini P, Zaniboni M. Bone augmentation procedures in implant dentistry. Int J Oral Maxillofac Implants 2009; 24 (Suppl): 237-259.

40. Sohn DS, Lee JS, Ahn MR, et al. New bone formation in the maxillary sinus without bone grafts. Implant Dent. 2008; 17: 321.

41. Nedir R, Bischof M, Vazquez L, Szmukler-Moncler S, Bernard JP. Osteotome sinus floor elevation without grafting material: A 1-year prospective pilot study with ITI implants. Clin Oral Implant Res. 2006; 17: 679-686.

42. Atieh MA, Zadeh H, Stanford CM, Cooper LF. Survival of short dental implants for treatment of posterior partial edentulis: a systematic review. Int J Oral Maxillofac Implants 2012; 27: 1323-1331.

43. Corbella S, Taschieri S, Del Fabbro M. Long-Term Outcomes for the Treatment of Atrophic Posterior Maxilla: A Systematic Review of Literature. Clin Implant Dent Relat Res. 2013 May 8. doi: 10.1111/cid.12077. [Epub ahead of print]

44. Avila G, Wang HL, Galindo-Moreno P, Misch CE, Bagramian RA, Rudek I, Benavides E, Moreno-Riestra I, Braun T, Neiva R.. The influence of the bucco-palatal distance on sinus augmentation outcomes. J Periodontol 2010; 81: 1041-1050.

45. Soardi CM, Spinato S, Zaffe D, Wang HL. Sinus floor augmentation with mineralized human bone allograft in sinuses of different size: An histologic and histomorphometric analysis. Clin Oral Implants Res 2011; 22: 560-566. 